\title{
Gelenekten Geleceğe Yöresel Kültürün Taşınmasında Festivallerin Rolü
}

\author{
İmran GÜNDÜZ ALPTÜRKER ${ }^{1}$ ve Hakan ALPTÜRKER ${ }^{2}$
}

$\ddot{O} z$

Festivaller ulusal ya da yerel düzeyde organize edilen ve insanların beraber eğlenebildiği toplantılar, kutlamalar olarak değerlendirilmektedir. Kültür aktarımının yoğun bir şekilde gerçekleştiği bu organizasyonların düzenlenmesinde ise yerel yönetim birimlerinden olan belediyeler etkin bir şekilde rol almaktadır. Türkiye'nin değişik il ve ilçelerinde; adları, kültürel ve sanatsal yönleri veya yer yer içerikleri birbirinden farklı olsa da pek çok festival düzenlenmektedir. Pek çok amaca birden hizmet eden Uluslararası Silifke Müzik ve Folklor Festivali de bunlardan biridir. Bu çalışmada 1974 yılından bu yana düzenlenen Uluslararası Silifke Müzik ve Folklor Festivali’nin kültür aktarımında ve korunmasındaki işlevi ve önemi değerlendirilmiştir. Nitel araştırma yöntemlerinden doküman incelemesinin kullanıldığı bu çalışmanın verileri, Silifke Belediyesi'nin arşivinde yer alan, 1974-2018 yılları arasında yayımlanmış "Uluslararası Silifke Kültür Haftası"nı konu alan dokümanlardan elde edilmiştir. Kırk altı yıllık yolculuğu olan bu festivalin; gelenekle ilişkilendirilerek, somut anlamda geleneğe ve tarihe yaslanan içeriğiyle "insanlar tarafindan seyredilen bir gösteri değil, herkesin katıldığı" bir etkinlik olduğu; kültürel belleğin sunumu ve icrasında -korunması bağlamında- uygulamalı halkbilimin amaçladığ1 teori ve pratiğin birbirini bütünlediği içeriğiyle "uygulayarak" ve "yayarak" yaşatmak anlayışının bilinçli ve sistemli örneklerini festival bağlamında ortaya koyduğu görülmektedir. Bu bağlamda da festivallerin kültür koruma sürecinde bir aktarım aracı olarak kullanılabileceği/kullanıldığı; "turistik" ve "ticari” bir etkinlikten daha fazlasına yer verdiği tespit edilmiştir.

Anabtar Kelimeler: Halkbilim, Toplumsal uygulamalar ve ritüeller, Festival, Kültür ve aktarım, Yerel yönetimler

\section{The Role of Festivals in Transporting Local Culture from Tradition to the Future}

\begin{abstract}
Festivals are considered as meetings, celebrations where people can have fun together at national or local level. In the organization of these events, where the cultural transmission is carried out intensively, the municipalities, which are the local government units, are actively involved and have been authorized by law to provide such cultural and artistic services. In different provinces and districts of our country; although their names, cultural and artistic aspects, or even their content are different from each other, many festivals are organized. International Silifke Music and Folklore Festival, which serves many purposes, is one of them. In this study, the function and importance of the International Silifke Music and Folklore Festival, which has been organized since 1974, in cultural transfer and preservation has been evaluated. The data of this study, in which the document review is used as one of the qualitative research methods, has been obtained from the documents on the "International Silifke Culture Week" published in the archive of the Municipality of Silifke between 1974-2018. It is an event that this festival which is forty-six-year journey, is an activity not as a spectacle watched by human beings but with its content that is tied to tradition and with historical content; and in the context of the, performance, presentation and conservation of cultural memory, provides the conscious and systematic examples of an understanding of "applying" and "spreading" the theory and practice aimed by the applied folkloristic with the content integrated with each other in the context of the festival.
\end{abstract}

Key Words: Folklore, Social practices and rituals, Festival, Culture and tranmission within generations, Local administration

\section{Atıf İçin / Please Cite As:}

Gündüz Alptürker, İ. ve Alptürker, H. (2021). Gelenekten geleceğe yöresel kültürün taşınmasında festivallerin rolü. Manas Sosyal Arasttrmalar Dergisi, 10(2), 1409-1422.

Geliş Tarihi / Received Date: 19.09.2020

Kabul Tarihi / Accepted Date: 14.01.2021

\footnotetext{
${ }^{1}$ Dr. Öğr. Üyesi - Mersin Üniversitesi Fen Edebiyat Fakültesi, ichimran@gmail.com

(iD) ORCID: 0000-0001-7445-5081

2 Öğr. Gör. Dr. - Selçuk Üniversitesi Silifke Taşucu Meslek Yüksekokulu, alpturker@gmail.com

(iD ORCID: 0000-0002-4389-0715
} 


\section{Giriş}

Toroslar'dan Akdeniz'e kosa kosa ulasalim

Neşeli ve güzel günleri hep beraber yașayalim

Yirmi Mayıs Silifke' de festivalde buluşalım

(Silifke Belediye Başkanlığ1, 2013, s. 22).

Festivaller geçmişin, bugünü ve geleceği besleyecek şekilde değerlendirilmesi açısından kültür aktarımının canlı bir şekilde sağlandığı etkinliklerdendir. Kültürel mirasın sürdürülebilirliği için yerel halkın katılımcı süreçlerle bilinçlendirilmesinin ya da gizil öğrenme yaratılmasının en etkili ortamlarındandır. "Her türlü toplumsal etkinlik, şenlik, festival, dinî/resmî tören veya bayramlar katılan bireylere birçok firsat sunar." (Balkaya, 2013) ${ }^{3}$, bu nedenle dünyadaki toplumların birçoğu kutlamalar, şölenler için belirli zamanlar ayırmıştır. Hayatın bir döneminden diğerine geçişte, bir mevsimden diğerine geçiş dönemlerinde ya da bir liderin, bir halk kahramanının tarih sahnesine çıkması ya da tarihî bir olayın yıl dönümü gibi bir topluluğun ya da grubun değerli anlarının kutlamaları (Smith, 2009, s. 341) hemen hemen her toplumda görülür. Takvimsel olarak belirlenen aralıklarla (Stoelle, 2009, s. 334) düzenlenen bu kutlamaların zamanını ise kimi zaman yerli üretim şartları, kimi zaman da genel bir "takvim geleneği” belirler. Mevsimlik bayramların kutlama zamanları iklim ve doğa koşullarına bağlı olarak farklılık gösterebilmektedir. Örneğin koç katımı; kışın kısa sürdüğü, baharın erken geldiği bölgelerde güz başlarında, baharın geç geldiği yerlerde ise güz sonlarında yapılır. Buna karşılık Nevruz, Hidrellez gibi bayramlar her yerde aynı tarihlerde kutlanır. Topluluk için anlam ifade eden bütün bu özel anlar, kutlama ile doldurulduğunda festival olarak adlandırılır (Smith, 2009, s. 341). Resmî ve dinî bayramlar gibi kimi kutlamalar bütün ülke halkının ortak bir değeri olurken, kimileri sadece belli bir yöre halkının ortak değerini oluşturabilmektedir.

Toplum yaşamında kökleşmiş amaçlara hizmet eden kutlamalar aynı zamanda pek çok işlevi de içinde barındırır. İnsanları bir araya getiren festivaller de bayramlar gibi insanların, toplumun birlik ve beraberliğini oluşturmak, kaynaşmalarını sağlamak, karşılıklı sevgi ve saygının meydana gelmesini temin etmek ve bunun bireylerin bilincinde yer etmesini sağlamak için fırsat sunan bir ortam yaratmaktadır. Bu hâliyle festival vasitasıyla bir araya gelen halkın görünümü, Turner'ın komünitas kavramına denk düşmektedir. Topluluğun tüm üyelerinin katıldığı; aralarında yoğun bir duygudaşlık ilişkisinin hâkim olduğu ve istedikleri için, gönüllü olarak orada olan katılımcılardan oluşan bir komünitas. Bu topluluk, "Yapısız veya basit yapılı veya nispeten ayrımlaşmamış bir komünitas, bir topluluktur" (Turner, 2018, s. 97). Yaşlı, genç, fakir, zengin, köylü, kentli gibi farklı kesimlerden ve pek çok kişiden oluşan homojen bir topluluktur. Smith'e göre topluluğun üyeleri festivallerde bir araya gelmekte ve etkileşimde bulunmaktadırlar. Bu bağlamda festival, sosyal bağlıllğı artırmakta ve bireyin veya grubun bir topluma entegrasyonunu sağlamaktadır (Smith, 1972 akt.: İmirgi, 2005, s. 35-36). Festival, "kamusal eğlence kültürü” (Şeyben, 2011, s. 53) ve birlikte eğlenme kültürü aracıllğıyla yaşlı, genç kuşakları bir araya getirerek sosyalleşmeye; bu sosyalleşme süreci de kültürel sürdürülebilirliğe katk1 sağlamakta; kuşaktan kuşağa aktarımın ve kültürel sürekliliğin sağlanmasının olanaklı kılındığı zamanları oluşturmaktadır. Bu sayede toplumsal belleğin sürekliliğine katkı sağlayacak ortamlar yaratılır, neticede "Bellek her zaman bir bireye 'ait'tir, ama bu bellek toplumsal olarak belirlenir; ... toplumlar üyelerinin belleğini belirler. En kişisel anılar bile sadece sosyal grupların iletişimi ve etkileşimi üzerinden oluşur.” (Assman, 2015, s. 44). O nedenle de grubun üyelerine, içerisine anılarını yerleştirebileceği bir çerçeve sunacak ortamlar yaratılması bu bağlamda önemlidir. Çünkü "Hafızamız öğrenilmiş tarihe değil, yaşanmış tarihe dayanır." (Halbwachs, 2017, s. 53) ve kollektif hatıralar, bireysel hatıraların üzerine eklemlendiği durumlarda daha kullanışlı ve güvenilirdir (Halbwachs, 2017, s. 55). Bu nedenle toplumsal uygulamalar bireyi, üyesi olduğu toplumsal gruba bağlayan bağları güçlendirir yanı sıra topluluk içinde gerçekleştirilmesi nedeniyle toplumsallaşma sürecine de katkı sağlamaktadır.

"Festival iletişimi katılımcıları aktif olarak birbirine bağlar." (Stoelle, 2009, s. 335) ve bu tür kutlama anlarında bir araya gelen topluluk üyeleri kolektif temsillerle ve sembollerle topluluk kimliğini pekiştirir ve yeniden üretir (Yldırım, 2014, s. 64). Bu sayede festivaller, katılımc1 her bireyin grup bilincinin yükselmesine, aidiyet duygusunun güçlenmesine katkı sağlamaktadır. Grup bilincinin yükselmesi ve grup kimliğinin pekişmesi, bireyi kimlik bunalımından kaynaklanan ve yabancılaşmayla sonuçlanan

3 Balkaya, A. (2013). Sarlkamıs’ta Bilinmeyen Yüzyllık Sosyal Olumlama Argüman: Karaurgan Karakucak Güreşleri. Web: https://docplayer.biz.tr/21620841-Sarikamis-ta-bilinmeyen-yuzyillik-sosyal-olummlama-argumani-karaurgan-karakucakguresleri.html adresinden 26 Mart 2019'da alınmıştır. 
olumsuzluklara karşı korur (Karaman, 2010, s. 232). Bir grubun üyesi olma hazzını yaşayan birey "Grup tarihini hatırlayarak ve kökenine ait hatırlama figürlerini belleğinde canlandırarak kimliğinden emin olur." (Assman, 2015, s. 60). Bu anlamda, festivaller, toplumsal grubun kendisine inancinı periyodik olarak tazelemesini olanaklı kılmaktadır. Ayrıca yaşlı ve genç kuşağın iletişim hâlinde oldukları, birlikte eğlendikleri festivaller sayesinde kültürün kuşaktan kuşağa aktarımı aynı zaman dilimi içinde olanaklıdır.

Kültür aktarımının yoğun bir şekilde gerçekleştiği bu organizasyonların düzenlenmesinde yerel yönetim birimleri etkin bir şekilde rol almaktadır ve bu tür kültür-sanat hizmetlerinin sunulması hususunda kanunen de yetkilendirilmişlerdir. Bir tür yerel hizmet olan festivaller genellikle, "yerel halkın müşterek ihtiyaçlarını karşılamak amacıyla kurulan yerel yönetimler"ce (Keleş, 2000, s. 21; Nadaroğlu, 2001, s. 3; Bayrakc1, 2019, s. 18) organize edilmektedir. Festival organizasyonu ilgili yerel yönetim biriminin karar organı olan meclisin alacağ çok il ve ilçede adları, kültürel ve sanatsal yönleri veya yer yer içerikleri birbirinden farklı olsa da birçok festival düzenlenmektedir. Festivaller, yerel yönetimlerin bilinçli çabalarılla yöresel değerlerin özgün çekiciliklere dönüsstürüldüğü bir uygulamadır. Yerel yönetimler bu tür uygulamalar ile kültürün korunması ve aktarımına katkı sunmaktadırlar.

Nebi Özdemir’in ifadeleriyle, "21. asır "kültür asrı olacaktır.” Bu nedenle de Türkiye’nin gelecekteki en önemli gücünü, kültürel belleği ve bu bellekten etkili bir şekilde yararlanan uzmanları oluşturacaktır. Ulusal ve kentsel ölçekte kültürel bellekten hareketle özgün ürünler yaratacak, tanitacak ve değerlendirecek çok yönlü kültür profesyonellerine ihtiyaç vardır.” (Özdemir, 2008, s. 20). Bu bağlamda yerel yönetimleri bu görevi yerine getirebilecek "kültür profesyonelleri’"nden biri olarak değerlendirmek olanaklıdır.

Geçmişin bugünü ve geleceği besleyecek şekilde değerlendirilmesi açısından, kültür aktarımının canlı bir şekilde sağlandığı etkinliklerden olan festivaller, kesinleşmiş karakteristik özellikleri olmayan, amaç bakımından çok yönlü olabilen, ses ve görüntü ağırlıklı ve yapıca karmaşık olan, halkın katılımı ile gerçekleşen ulusal (Stoelle, 2009, s. 334) ya da yerel düzeyde organize edilen kutlamalardır. Bu bağlamda festivaller insanların beraberce eğlenebildiği toplantılar, kutlamalar olarak değerlendirilmektedir (Smith, 2009, s. 344). Silifke Belediyesi tarafından 1974 yllından beri Silifke'de düzenlenen ve pek çok amaca birden hizmet eden "Uluslararası Silifke Kültür Haftası" da bunlardan bir tanesidir.

Mersin'in Silifke ilçesi, çeşitli dinlerin ve kültürlerin buluştuğu önemli merkezlerden biridir. Silifke ve çevresi, beş bin senelik tarihî bir dokuya sahiptir. Bu coğrafyada pek çok devlet hüküm sürmüş, imparatorluklar gelip geçmiştir. Pek çok medeniyete ev sahipliği yapmış olan, değişik dinleri ve kültürleri buluşturan Silifke, köklü bir tarihe ve zengin bir kültürel mirasa sahiptir, hem toplumsal hem de kültürel açıdan önemli olaylara sahne olmuştur. Bunun sonucu olarak da sahip olduğu sözlü ve yazılı edebiyat geleneği, kültür ürünleri oldukça zengin bir görünüm arz etmektedir.

Konargöçer bir toplumun torunları olan Silifke halkının kışın sahillerde, yazın yaylalarda yaşama geleneği vardır. Yayla ve sahil arasındaki göçler, bu göçler esnasında yöre halkının karşılaş̧ı̆̆ı olaylar; yöre halkının ürettiği ürünler, beslediği hayvanlar; bu hayvanlardan üretilen ve türkülere konu olan yoğurdu ile çökeleği yerelden ulusala taşınmış değerleridir. Bunların yanı sıra sözlü kültür ürünleri de oldukça zengin bir görünüme sahiptir. Ayrıca bu sözlü kültür ürünlerinin bazılarının müzikle birleştirilmesi neticesinde ortaya çıkan "Yayla Yolları", "Türkmen Kız1", "Ger Ali", "Sallama", "Keklik", "Zeytin Dalları", "Tımbılll", "Mandilli", "Portakal Zeybeğı", "Silifke Zeybeği", "Çaya Vardım Zeybeği", "Kibrı Zeybeği”" ve "Tek Zeybek" gibi halk oyunları yaşanan Yörük-Türkmen kültürünün zenginliğini ortaya koyan örneklerindendir.

Kültürel kaynaklar açısından zengin bir bölge olan Silifke, bu kültürel miras ürünlerini tanıtmak, yaşatmak ve gelecek kuşaklara aktarmak gayesi ile 1974 yllindan bu yana, her y1 20-26 Mayıs tarihleri arasında pek çok etkinliğin yer aldığı "Uluslararası Silifke Kültür Haftası" düzenlemektedir. Festival kapsamında yer alan etkinliklerle bir taraftan geleneksel bellek sergilenirken, canlandırlırken, gelecek kuşaklara aktarllırken, diğer taraftan bu süreç kültürel ekonomik değere dönüştürülmektedir.

$\mathrm{Bu}$ çalışma festivallerin kültür aktarımındaki rolü ve önemini araştırmak amacıyla yapılmıştır. Bu kapsamda UNESCO tarafindan 17 Ekim 2003 tarihinde kabul edilen ve Türkiye'nin de 2006 yllinda taraf olduğu Somut Olmayan Kültürel Mirasin Korunmasi Söəlessmesi hükümlerine göre korunması ve gelecek kuşaklara aktarılması için, "halkbilimi ürünlerinin artık 'yaşatmak için yaymak' düşüncesiyle uygulanması"

${ }^{4}$ Konu ile ilgili http://www.silifke.bel.tr/turkulerimiz-sayfa.html adresinden ayrıntılı bilgi edinilebilir. 
(Oğuz, 2013, s. 10) bağlamında ve yerel bilinçlenmenin güzel örneklerinden biri olarak Silifke'de kırk altı yıldır düzenlenen "Uluslararası Silifke Kültür Haftası" etkinlikleri ve bu etkinliklerin kültür koruma kapsamındaki işlevi ve önemi değerlendirilmiştir. "Uluslararası Silifke Kültür Haftası”nın örneklem olarak seçilmesinde, 1974 yılından bu yana, bir başka ifade ile kırk altı yıldır, periyodik olarak düzenlenmesi belirleyici olmuştur.

Literatür incelendiğinde festivalleri çeşitli açılardan değerlendiren çalışmalar olduğu görülmektedir. Bu çalışmaların bir kısmı festivalleri turizmle ilişkilendirerek, festivallerin ekonomik katkıları üzerineyken (Prentince and Anderson, 2003; İlban ve Kömür, 2019) bir k1sm1 katılımcilarının, festival hakkındaki alg1 ve memnuniyetlerini araştırmaya yöneliktir (Tayfun ve Arslan, 2013; Karaca, yıldırım ve Çakıc1, 2017; Buzcu ve Oğuz, 2019). Ayrıca literatürde “Uluslararası Arası Silifke Müzik ve Folklor Festivali”ni konu alan iki farklı çalışmaya rastlanmıştır.

Süslü, Eryılmaz ve Demir (2019) yaptıkları çalışmada, festival turizminin bölgesel kalkınmaya etkilerini tespit etmeye çalışılmışlar, çalışma sonucunda bölgede festival turizmine yönelik ilginin fazla olduğuna fakat reklam, tanıtım, pazarlama faaliyetlerinin daha etkin hâle getirilmesi gerektiği gibi birtakım sonuçlara ulaşmışlardır.

Saçlı (2020) tarafindan yapılmış çalışmada ise, 2019 yılı "Uluslararası Arası Silifke Müzik ve Folklor Festivali” katılımcılarına anket uygulaması yapılarak, festival katılımcılarının algıladıkları kültürel etkileşim boyutları belirlenerek ve kültürel etkileşim ile festival memnuniyeti arasındaki ilişki ortaya konulmuştur. Çalışmanın sonuçlarına göre, katılımcıların kültürel etkileşim düzeylerinin yaş ve eğitim düzeyleri bakımından farklılaştığ1 ve katılımcıların kültürel etkileşim düzeyleri ile festival memnuniyetleri arasında pozitif yönlü bir ilişki olduğu tespit etmişlerdir.

Bununla birlikte literatürde festivallerin kültür ile ilişkisini çeşitli açılardan inceleyen çalışmalara rastlamak mümkündür (Atak, Tatar ve Tunaseli, 2017; Yeşilyurt, 2018). Ancak yapılan çalışmalar arasında festivallerin kültür aktarımındaki rolü ve önemini değerlendiren herhangi bir çalışmaya rastlanılmamıştır. $\mathrm{Bu}$ çalışmada yerel yönetimlerin sunduğu kültürel nitelikli hizmetlerden birisi olan festivallerin kültür aktarımındaki rolü ve önemi değerlendirilmiştir. Çalışma yerel halkın birçok ihtiyacını karşılayan yerel yönetimlerin sunmuş olduğu kültürel nitelikli hizmetlerden birisi olan festivallerin işlevselliğini değerlendirme açısından oldukça önemlidir.

Çalışmada nitel araştırma yöntemi kullanılmış ve doküman incelemesi yapılmıştır. Doküman incelemesi, araştırılması planlanan olgu ya da olay hakkında bilgi içeren yazılı materyallerin analiz edilmesidir (Yıldırım ve Şimşek, 2016). Bu araştırmada kullanılan verileri elde etmek amacıyla Silifke Belediyesi'nin arşivinde yer alan, 1974-2018 yılları arasında yayımlanmış "Uluslararası Silifke Kültür Haftası"nı konu alan dokümanlar incelenmiş ve yorumlanmıştır.

\section{Uluslararası Silifke Müzik ve Folklor Festivali’nin Kültür Aktarımındaki Rolü ve Önemi}

Silifke festivalin düzenlenmeye başlanmasının gözleme dayalı bir hikâyesi vardır. İngiltere'nin 3-4 bin nüfuslu Llangollen şehrinde yıllardır düzenlenen ve 1960 yılında uluslararası nitelik kazanan festivale Türkiye'den de Silifke, Bursa, Elazı̆̆g, Antep ve Karadeniz halk dansları ekiplerinden oluşan 45 kişi katılır. 1700 kişilik icracı katılımcıyı ağırlayan Llangollen şehri, festival boyunca günde 30000 kişiyi misafir eder. Festivalde bütün halk görev alır, icracı misafirler ikişer üçer kişilik gruplar hâlinde Llangollen halkının evlerinde misafir edilir. Ayrıca bütün kasaba halkı festivalde görevlidir ve bunu layıkıla yerine getirirler. Örneğin kadınlar yemek pişirip aşçılık yapar, gençler garsonluk, teşrifatçılıkla uğraşırken bazıları bilet satışı, bazıları mihmandarlık görevini üstlenir. Beldede sosyal, ekonomik ve kültürel hareketlilik muhteşem bir görünüme sahiptir ve Silifke ekibi bundan çok etkilenir. O y1llarda Silifke Folklor Derneği camiasında Silifke festivali düzenleme fikri oluşmuş ve çabası içine girilmiştir (Silifke Belediye Başkanlığ1, 2013, s. 21).

İlk olarak 1974 yılında "Uluslararası Silifke Müzik ve Folklor Festivali” adiyla düzenlenen festival; 1996 yılından itibaren, festival programında yer verilen etkinliklerin kapsamı genişleyince 20-26 Mayıs haftasını kapsayacak şekilde organize edilmeye ve 1996 yılında "Uluslararası Silifke Kültür Haftası" olarak adlandırılmaya başlanır. 2017 yılından itibaren ise "Uluslararası Silifke Müzik ve Kültür Festivali”" olarak adlandırılmıştır. Uluslararası Silifke Kültür Haftası'nın düzenlenme amaçları; 1983 yılında hazırlanan tüzükte; folklor, tarih, turizm ve doğal zenginliklerini yurt içinde ve yurt dişında tanıtmak, bunun için araştırmalar yapmak, uluslararası kültür ve sanat alışverişine sahne olmak, ulusal ve uluslararası tanışma, dayanışma ve birlikte yaşayıp eğlenilmesine fırsat yaratarak dünya barışının gerçekleştirilmesine katkıda bulunmak, her türlü sanat gösterileri ve yarışmaları düzenleyerek, yeni yeteneklerin ortaya çıkmasına imkân 
hazırlamak, yörenin ekonomik gücünü ve sosyal yaşantısını geliştirmek, turizm faaliyetlerine yoğunluk ve canlılık kazandırmak (Silifke Belediye Başkanlığı, 2013, s. 88) olarak belirtilmiştir. Bu amaçlar doğrultusunda uzun yıllardır düzenlenen; programında farklı sanat dallarına ve türlerine yer veren Silifke festivalinin uzun yllara dayanan geçmişi, bu süreçte elde edilen deneyim ve uluslararası ölçekte gerçekleşiyor olması festival programının içeriğini çeşitlendirmekte ve zenginleştirmektedir. Açılan el sanatları, ağaç işleri, seramik, giyim, nakış, resim ve heykel sergilerinde, yapılan yemek, ses ve spor yarışmalarında birçok yeteneğe firsat verilmektedir. Örneğin 1977 yllında festivalde düzenlenen Türk halk müziği amatör ses yarışmasında, Sabahat Akkiraz ve Seyfettin Tomakin birinci olmuştur. Geleneksel yaşam biçimini konu alan yörük göçü, yörük çadırı, sünnet şöleni, köy dügünü gibi uygulama ve programlarla yeni nesiller bilgilendirilmekte, amatör tiyatro gruplarının çalışmaları desteklenmekte, edebi alanda çalışma yapanlar halka tanitilmakta; halk paneller ve konferanslarla bilgilendirilmekte, konserlerle eğlendirilmektedir.

Programda müzik eksenli olarak festival haftası içerisinde ses sanatçlarının -festivalin ilk yıllarında Türk sanat ve halk müziği, son yıllarında ise pop müziği icra edenlerin- sahne aldığı bir konser neredeyse- her akşam düzenlenmiştir. Ayrıca festival kapsamında halkbilimi açısından çok kıymetli olarak değerlendirilebilecek bilimsel etkinlikler de yer almıştır. 15 Haziran 1977 yılında "Halk Ozanları, Mahalli Halk Oyunları, Türk Halk Oyunları" konulu açık oturum ile halk oyunlarının içinde bulunduğu durum tartışılmıştır. 21 Mayıs 1993 yılında Doç. Dr. Oğuz Makal'la "Sinemanın Dünü, Bugünü, Yarını", Yavuz Seçkin'le "Gelenekten Geleceğe Türk Resim Sanatı", 23 Mayıs 1993 yllında Sami Karaören ile "Dilimiz ve Şiirimiz" başlıklı söyleşiler ve 22 Mayıs 1995'te "Akdeniz Mutfağı" paneli, 27 Mayıs 1998'de "Halkoyunları Paneli” (Silifke Belediye Başkanlığı, 2013, s. 205) ve İrfan Ünver Nasrattınoğlu ${ }^{5}$ öncülüğünde 21 Mayıs 1996'da düzenlenen "Uluslararası Türkmen Kültürü” Sempozyumu'nda (Silifke Belediye Başkanllğı, 2013, s. 156, 157, 168, 184) sinemadan şïre, yemek kültüründen Sarrkeçililere pek çok konu konuşulup tartışılmış, halkın bilgilenmesi ve bilinçlenmesine olanak sağlanmıştır. İrfan Ünver Nasrattınoğlu öncülüğ̈ünde 24. Uluslararası Silifke Kültür Haftası etkinlikleri içerisinde "Uluslararası Türk Dünyas1 Kültür Sempozyumu" (Silifke Belediye Başkanlığı, 2013, s. 199), 1999 yllında ise "Osmanlı’nın 700. Kuruluş Y1ldönümü ve Türk Dünyası Sempozyumu” düzenlenmiştir.

Düzenlenen “Âşıklar Şöleni” ya da "Halk Ozanları Şöleni”yle Şeref Taşlıva, Rüstem Alyansoğlu, İsmail Cengiz Azeri, Ozan Dündar, Çukurovalı Âşık Mahmut Taşkaya, Tekirdağlı Âşık Zülfikar Divani, Çukurovalı Âşık Mahmut Taşkaya, Gürünlü Âşık Gülhani, Mersinli Âşı Ahmet Mertkul, Eskişehirli Âşı1k Sarıca Kız, Afyonlu Âşık Aslı Bacı gibi yurdun dört bir tarafından gelen âşıklık geleneğinin temsilcileri hem yerel hem de yurt dışından gelen katılımcılarla bir araya getirilerek bu geleneğin tanıtılması ve yaşatılmasına katkı sağlanmıştır. Âşıklar tarafından festival temalı yeni şiirler yazılıp icra edilmiştir:

Korosuna kulak ver, sazım iyi dinle

Yörï̈̈̈̈n çadirnda ayran iç de serinle,

Davul, klarnet, keman ve folklor ekibinle

Kutlanyor 20. Silifkee Festivali (Silifke Belediye Başkanlığı 2013, s. 154)

Ya da

Ela gǫ̈lerini sevdiğim dilber

Göster cemalini görmeye geldim

Festivalin derde derman dediler

Gerçek mi sevdiğim, sormaya geldim (Silifke Belediye Başkanlığı, 2013, s. 154) bu icraların örneklerindendir.

\footnotetext{
${ }^{5}$ Festivalin üçüncü yılından itibaren düzenleme komitesinde yer alan ve festival organizasyonu ile tanıtımında görev ve sorumluluklar üstlenmiş Silifke'nin fahri hemşehrisidir.
} 


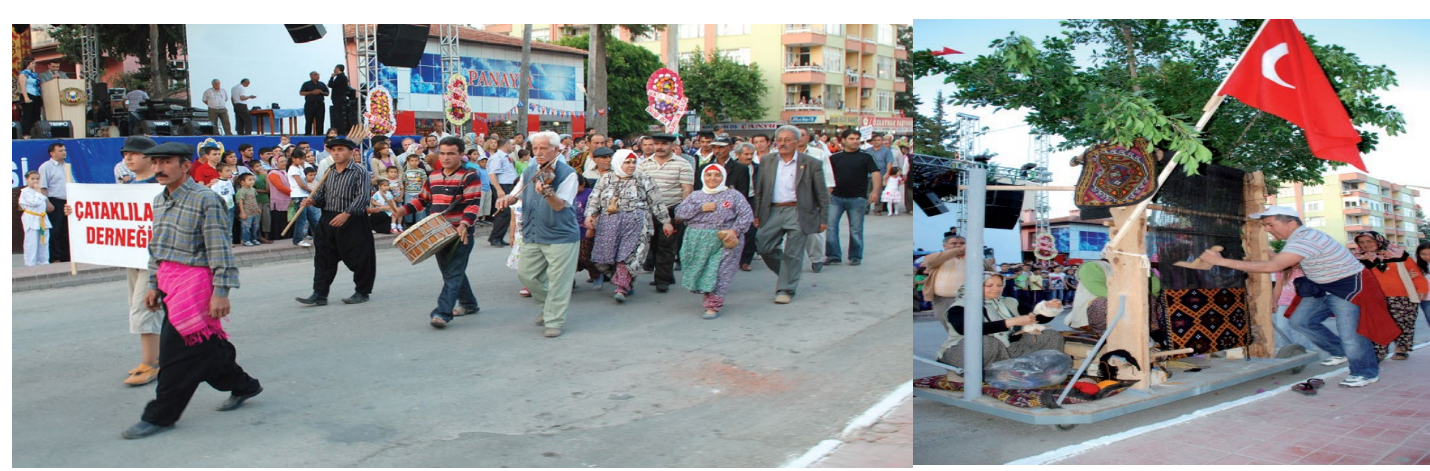

Fotoğraf 1. Kortej yürüyüsü, Cataklular Derneği

Fotoğraf 2. Istar

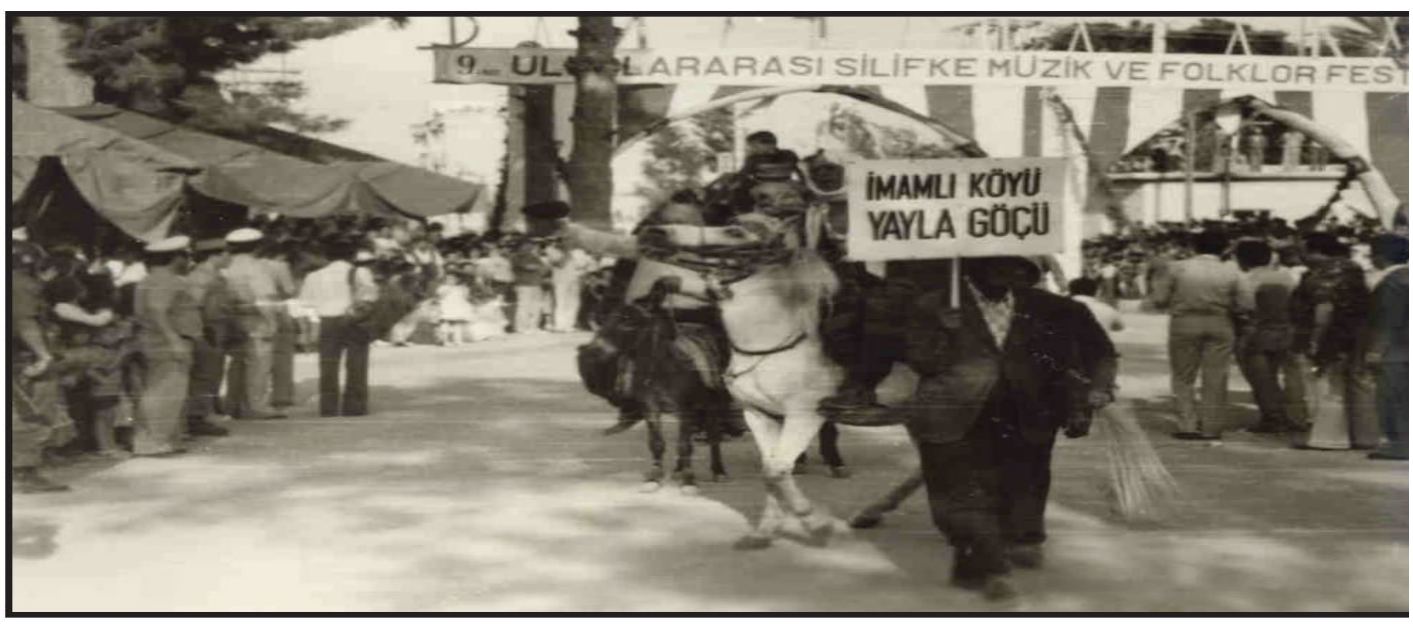

Fotoğraf 3. Kortej yürüyüşü, Imaml köyü yayla göçü (1983)

Her yıl 20 Mayıs'ta ana mekân olarak ve Silifke'nin Meydanı olarak adlandırılan Atatürk Anıt'ında; halk oyunları ekipleri, festival koroları, âşıklar, yöresel sanatçılar, düğün alayı, göç kervanı, avc1lar, sporcular, okullar, resmi kuruluşlar, bankalar, kooperatifler ve derneklerin temsilcilerinin yer aldığ1 festival kervanının yürüyüşü -son dönemlerdeki adlandırmayla kortej yürüyüşü- ve sonrasında ilçe belediye başkanının anıta çelenk koyması ve açılış kurdelesini kesmesiyle festival başlamaktadır.

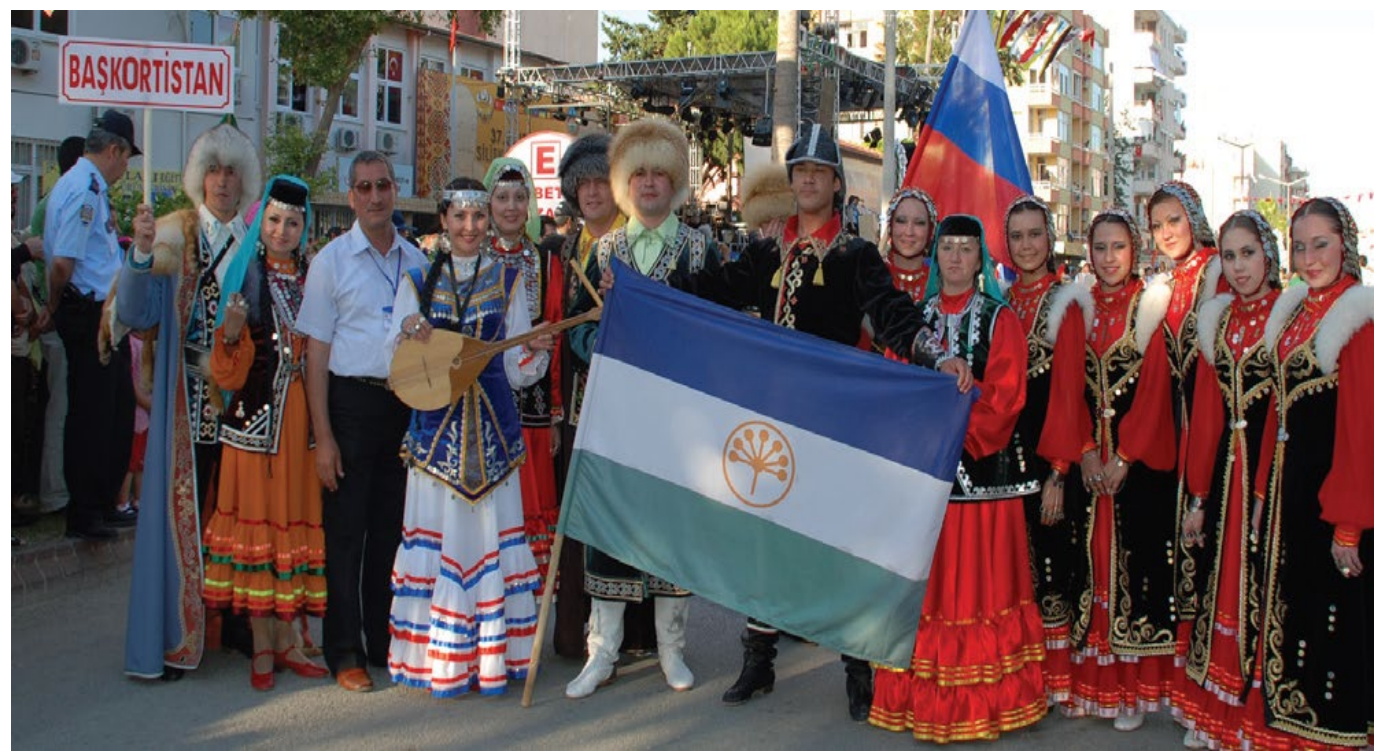

Fotoğraf 4. Başkurdistan halk danslar topluluğu

${ }^{6}$ Halı, kilim vb. şeyler dokunan tezgâh (TDK Derleme Sözlüğü, 1993:2489). 


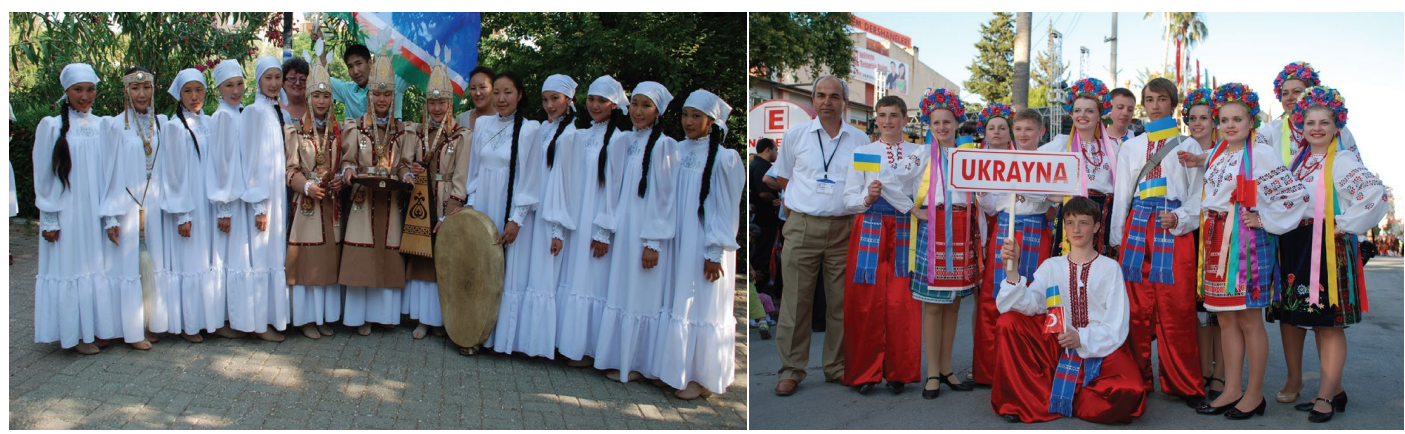

Fotoğraf 5. Yakutistan halk danslar topluluğu $\quad$ Fotoğraf 6. Ukrayna balk danslar topluluğu

Festival haftası içerisinde pek çok tezgâh açılıp sahne kurulmaktadır. Açılan tezgâhlarda çoğunlukla yöreye özgü ürünler satılmakta, kurulan sahnelerde çeşitli oyun, yarışma ve gösteriler yapılmaktadır. Yörenin halk dansları ekibi, mahalli sanatçıları, yöresel çalgıları, kukla gösterileri, Karagöz, Aşuk-maşuk ${ }^{7}$ ve köy seyirlik oyunlarının yanı sıra Kars, Gaziantep, Kırıkkale, Edirne, Eskişehir, Tokat, Manisa gibi yurt içinden ve Bulgaristan, Belçika, İtalya, Libya, Kosova, Romanya, Makedonya, Ukrayna, Kabartay-Balkar, Başkurdistan, Yakut Özerk Cumhuriyeti gibi pek çok yurt dışı halk dansları ekiplerinin gösterileri de yer almaktadir.

Stella Kladou'nun (2011, s. 44) aktardığına göre başarılı bir festival, kültürün aktif bir biçimde işlendiği festivaldir. Gelenek kökenli içeriklerden, "geleneğin/sözlü kültürün/yöresel kültür belleğinin" yerelin; sunumun içeriğini şekillendirdiği; el sanatları, mutfak-yemek, geleneksel giyim-kuşamın sunumunun yapıldığı organizasyonlar hem ülke içinden hem yurt dişından gelen katılımcılara tanıtılmakta hem de yöre halkı arasında canlı bir şekilde sürdürülebilir kilınmaktadır.

Festivaller kuşkusuz kentin kültür ekonomisi için en önemli gösterim, yeni ürünleri deneyimleme, sanat1 yaygınlaştırma ve sürdürülebilir kılma mekanizmalarından birisidir. En büyük özelliklerinin devamlılık göstermeleri olduğu dikkate alınırsa festivaller kültür sahasının vazgeçilmez k1lınmasında önemli bir rol oynar (Ada, 2011, s. 15).

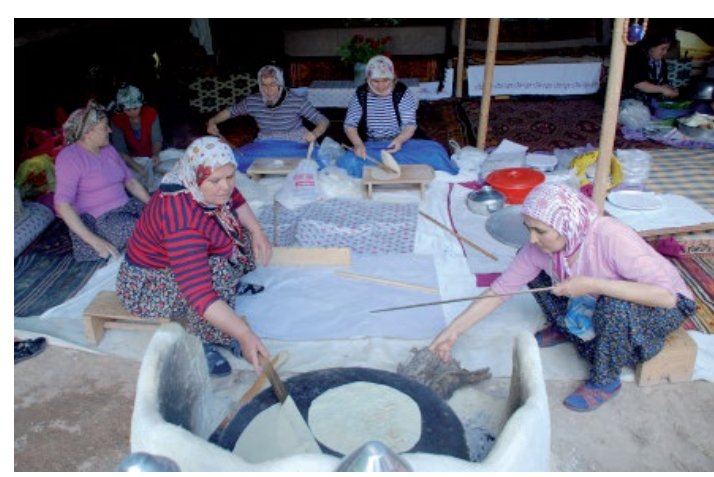

Fotoğraf 7. Sikma yapımı

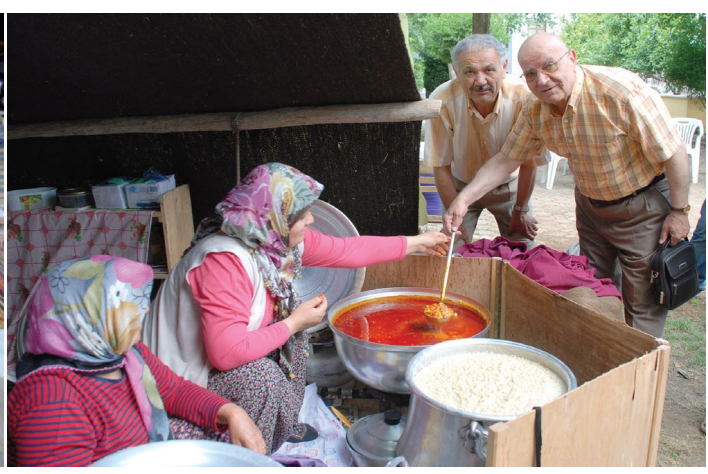

Fotoğraf 8. Keskeek ve yahni

\footnotetext{
${ }^{7}$ Bu konuda ayrıntılı bilgi için bakınız: Çıblak Coşkun, Nilgün (2018). "Mersin İli Koy Seyirlik Oyunlarından Deve Bollatması ve Aşuk Maşuk Oyunu”. Karadeniz 128-140.
} 


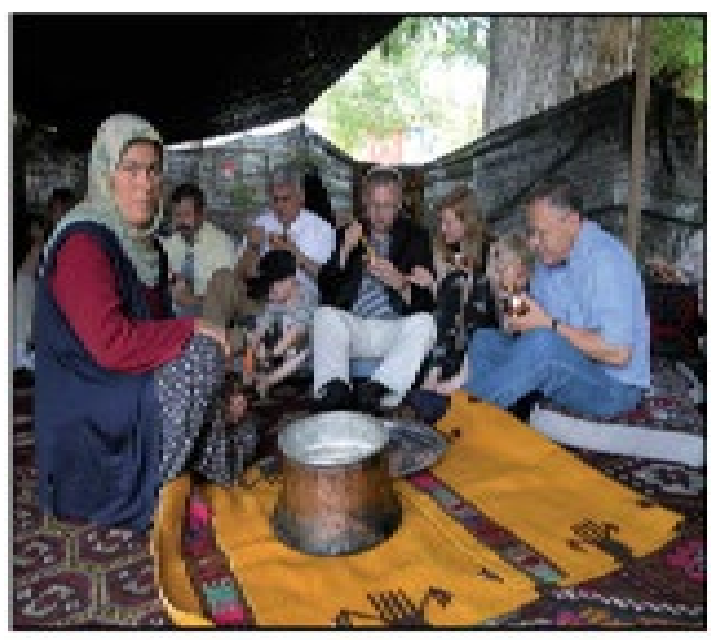

Fotoğraf 9. Yoğurt ikramı

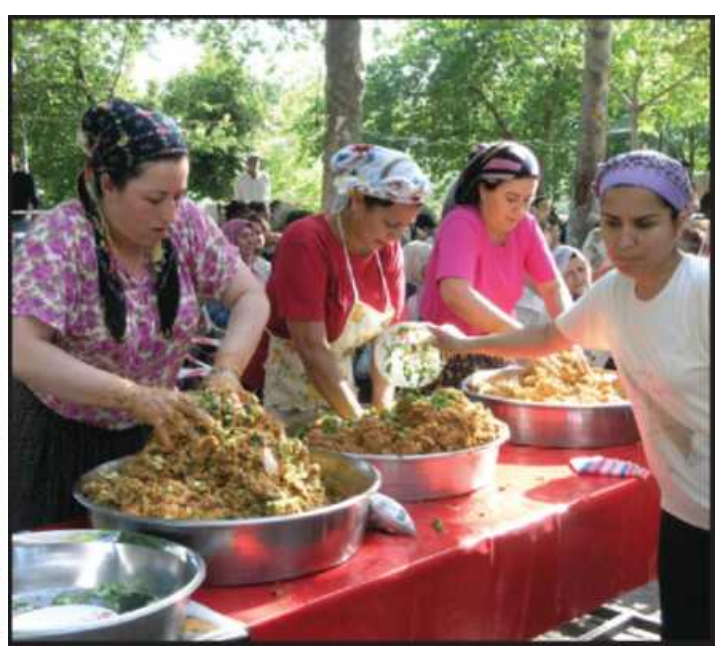

Fotoğraf 10. Batırı ikramı

“Toplumsal yeniden üretim/tüketim ilişkilerinin yapılandığı ve dağıtıldı̆̆ı” (Erdoğan, 2011, s. 80) festival kapsamında batırrk, sıkma, keşkek, yahni, yoğurt, ayran, çökelek gibi yöresel yiyecekler Göksu Irmağı boyunca köy derneklerince kurulan Yörük çadırlarında çoğu zaman saz ve söz eşliğinde halkın hizmetine sunulmaktadır. Beverly J. Stoeltje (2009, s. 337) "Festival" adlı çalısmasında festival yemeklerini gruba kimliğini cisimleştirme firsatı sunan unsurlar olarak tanımlar ve yemekler daima belli olur der. Silifke festivalinde de bu yemekler, vazgeçilmez ve değişmez unsurlar olarak sıkma ${ }^{8}$, keșkek, yahni, batırık, tantuni ve yayık ayranından oluşmakta; grup kimliğinin doğrulanmasına olanak vermektedir. Ayrıca festivalin düzenlendiği ilk yıllardan beri pek çok kez düzenlenen batırık ve yoğurt yapma yarışması da bu geleneğin sürdürülme sürecinin etkili yöntemlerinden biri olarak değerlendirilebilir.

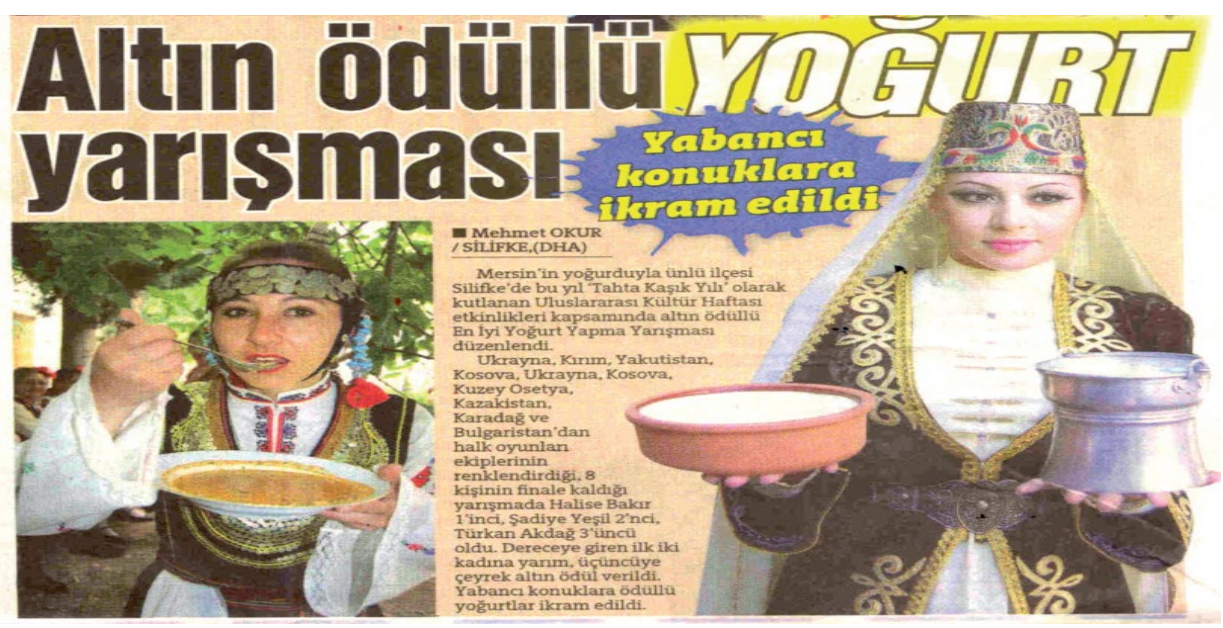

Fotoğraf 11. Festivalin 32. yll olan "yoğurt ynh"nda düzenlenen yoğurt yarısması

Etkinliğe katılanlar yöresel gelenekleri deneyimleyerek özgün içerik ve kimlik kazanmakta; bu sayede de birey bu tür etkinliklerle biz bilincine ulaşmaktadır. Yüzlerce kişi geleneksel yemekleri tüketirken, yöresel içerikle kimlik kazanır. Bireysel mutluluk ve toplumsal birliktelik açısından bu tür etkinlikler önemli işlevlere sahiptir. Popüler kültürle tek türleşen birey ve toplum, yöresel etkinliklerle özgünleşir (Özdemir, 2012, s. 159). Bu etkinliklerle bir taraftan geleneksel bellek sergilenirken, canlandırilırken, gelecek kuşaklara aktarılırken diğer taraftan yörede yaratılan ürünler kültürel ekonomik değere dönüştürülmektedir. Oğuz’a (2013, s. 76) göre "Türkiye, kendi yerel ve ulusal renklerini araştırmak ve yorumlamak, bu özellikleriyle yeryüzünde var olmaya devam etmek ve bu özelliklerini "pazarlayarak" bir gelir kalemi oluşturmak istiyorsa, kuramsal düzlemde halkbilimin gelecekteki önemini ve ulusal kalıtın küresele sunulmasının gereğini iyi kavramalı, uygulama düzleminde ise, bunun için gerekli olan kurumlaşmaları gerçekleştirmelidir." Bu bağlamda festival kapsamında, yerel unsurların ulusal ve sayıları az da olsa

\footnotetext{
${ }^{8}$ Sıkma: Bazlamadan daha ince açılmış bir hamurun sacda pişirildikten sonra içine çökelek, kavrulmuş çökelek, peynir ya da patates gibi çeşitlenebilen muhtelif malzemeler konulduktan sonra sarılıp sıkılması suretiyle yapılmaktadır.
} 
uluslararası katılımcılarla buluşturulması sağlanmaktadır. Ayrıca festival dönemlerinde yörenin ekonomik yaşamı da canlanmaktadır (Akarpınar, 2004, s. 28).

"Festivaller, kolektif olağanüstü olaylardır ve grup yaşamında kökleşmiş amaçlara hizmet ederler. Karşılıklılık ve paylaşılan sorumluluk sistemleri, prestij ve üretimin dağıtımı aracilığılla festivale katılımı ve katılımın devamlılığını sağlar. Pek çok festival, kişisel dini bağlılık veya kişisel icra için firsat sağlar ve bu firsat söz konusu durum için birincil bir güdüdür." (Stoltje, 2009, s. 334). Her türlü toplumsal etkinlik, şenlik, festival, dinî/resmî tören veya bayramlar katılan bireylere birçok firsat sunmaktadır. Festival tarihi içinde, festivalin kültür haftasına dönüşmesinden sonra gerçekleştirilmeye başlanan ve 2000 yllına kadar festival kapsamında sunulan geleneksel köy dügünleri ve kına geceleri de bu bağlamda değerlendirilebilir. Silifke yöresinin evlenme ritüellerine uygun olarak düzenlenen köy düğünlerinde evlenen kişiler, maddi imkânları yetersiz olduğu için evlenemeyen kişilerden seçilmektedir. Bu açıdan festival kapsamında yer alan köy dügünleri evlenen kişilere de hayallerini gerçekleştirme firsatı sunmaktadır. Bu dügünlerde taşıtlar, dügün salonu, müzisyenler, gelinlik ve damatlık, kuaför, nişan yüzükleri, kına gecesi gibi bütün masraf kalemleri kültür haftası komitesi tarafından karşılanmıştır. Düğün gerçekleştirilirken yörede bir köy dügünü içinde geleneksel olarak yapılan kız isteme, düğ̈n tarihi tespit etme, esbap kesme, okuntu ve dürü gönderme, bayrak dikme, düğün odunu yapma, tahıl döğme, kız evine tomgavutcu9 eşliğinde aşçı ve aşç1 çadır1 gönderme, düğünde çalgıcılara çalgıc1 başı görevlendirme, damat tıraşı, dürü ${ }^{10}$ karşıllğı̆nda davar ${ }^{11}$ getirme, düğün alayı yapma, çalgıyla davetlileri karşılama, oğlan evine çeyiz götürme, gelin alayı önüne ip germe, ata gelin bindirme, gelin indirme, geline indirmelik verme, geline ibrik teptirme, geline kapiya ballı yaprak yapıştırtma ve geline kapıdaki ipi kırdırma gibi ritüellerin tamamına yer verilmiştir. Ayrıca bütün halkın davetli olduğu bu düğünlerde, misafirler/katılımcılar evlenen çiftlere hediyeler de sunmuştur (Silifke Belediye Başkanlığ1, 2013, s. 222).

Silifke festivali iletişimsel, toplumsal, kültürel hatta ekonomik boyutlarıyla değerlendirildiğinde, Silifke halkı bu festival sayesinde geleneksel kültürden beslenerek sahip olduklarını/ürettiklerini değerlendirebilir hâle gelmiştir. Kültürün "gereksiz bir gider alanı" değill, "çok yönlü kalkınmayı sağlayan bir yaratma alanı" olduğunun göstergesidir. Festival yöresel geleneklerin, dolayısıyla ürün ve uygulamaların ulusal/küresel ölçekte tanınmasını, bir süre sonra da deneyimlenmesini sağlayacaktır. Bunun yanı sıra bütünleştirici, kaynaştırıc "hemşehrilik temelinde biz" bilincini oluşturmak ve yaygınlaştırmak işlevine de sahiptir. "Biz" bilinci küresel ölçekte oluşturulurken doğal olarak yöresel/sözlü kültür belleğinden yararlanılmakta; aynı zamanda bellek yitiminin önüne geçilmesi sağlanmaktadır. Bu bakımından değerlendirildiğinde de festival oldukça değerli ve işlevseldir. Bu nedenle somut olmayan kültürel mirasın korunması, kaydedilmesi, geliştirilmesi ve canlandırllarak geleceğe aktarılmasında festival önemli katkılar vermiş ve vermeye de devam etmektedir.

Yereli ve yerelde yaşayan tüm unsurları önemseyen Silifke Belediyesi, 2010 yllından beri düzenlenen “Türkçe Konuşan Ülkeler Arası Ses Yarışması” ile de Türk Dünyası ile ilişkiler geliştirip dostluklar kurulmasını olanaklı kılmıştır. TÜRKSOY ortaklığında organize edilen bu ses yarışmasıyla birleştirici kaynaştırıcı bir kültür politikası izlendiği ve bu yaklaşım doğrultusunda Türk Dünyası ile olan bağları artırıcı organizasyonlarla geçmişi geleceğe taşıma hedeflenmektedir (Silifke Belediye Başkanlığı, 2013, s. 406-407).

Festivallerin devamlılı̆̆nda festivalin canlılığı ve markalaşması önemli hususlardandır. Silifke festivali -örneklerde görüldüğ̈̈ üzere- sunduğu zengin içeriğiyle canllliğı yakalayabildiği gibi markalaşma sürecinde de büyük adımlar atmıştır. Sahip olunan kültürel birikimi yansıtan, yaşatan ve gelecek kuşaklar aktarmak amacıyla festivale 2000 yıllndan itibaren Silifke'nin kültürünü ve değerlerini yansıtan ayrı ayrı isimler verilmiştir. 2000 yllı "Türkmen Güzeli Yllı", 2001 yllı "Heybe, Çul, Çuval Yılı”, 2002 yllı "Aşuk-Maşuk Y1lı", 2003 yllı "Ham Çökelek Y1lı", 2004 yılı "Çilek Yılı", 2005 y1lı "Yoğurt Yılı", 2006 yllı "Keklik Yılı", 2007 yll yani festivalin 34. yllı -2011 yll itibarıly UNESCO İnsanlığın Somut Olmayan Kültürel Mirasının Temsili Listesi'ne alınmış olan- "Keşkek Yllı", 2008 “Türkü Yllı", 2009 yılı "Batırık Yllı", 2010 yıll "Cavit Erden Sanat Y1lı", 2011 yllı "Mavi Yengeç”, 2012 yll “Tahta Kaşık”, 2013 y1lı "Mavi Akdeniz”, 2014 yllı "Yörük Yılı", 2015 ve 2016 "Göksu Yıllı" ilan edilmiş; görünür kıllnan somut olmayan kültürel miras ürünlerinin kentlere egemen olan endüstriyel kültüre karşı korunması sağlanmıştır.

\footnotetext{
9 Tomgavut > tohum kavut: tahıl ve kavrulmuş tahıl ürünleri.

10 Dürü: Düğüne çağrrlanlara düğün sahibi tarafindan verilen armağan.

11 Davar: Koyun ve keçiye verilen ortak ad.
} 


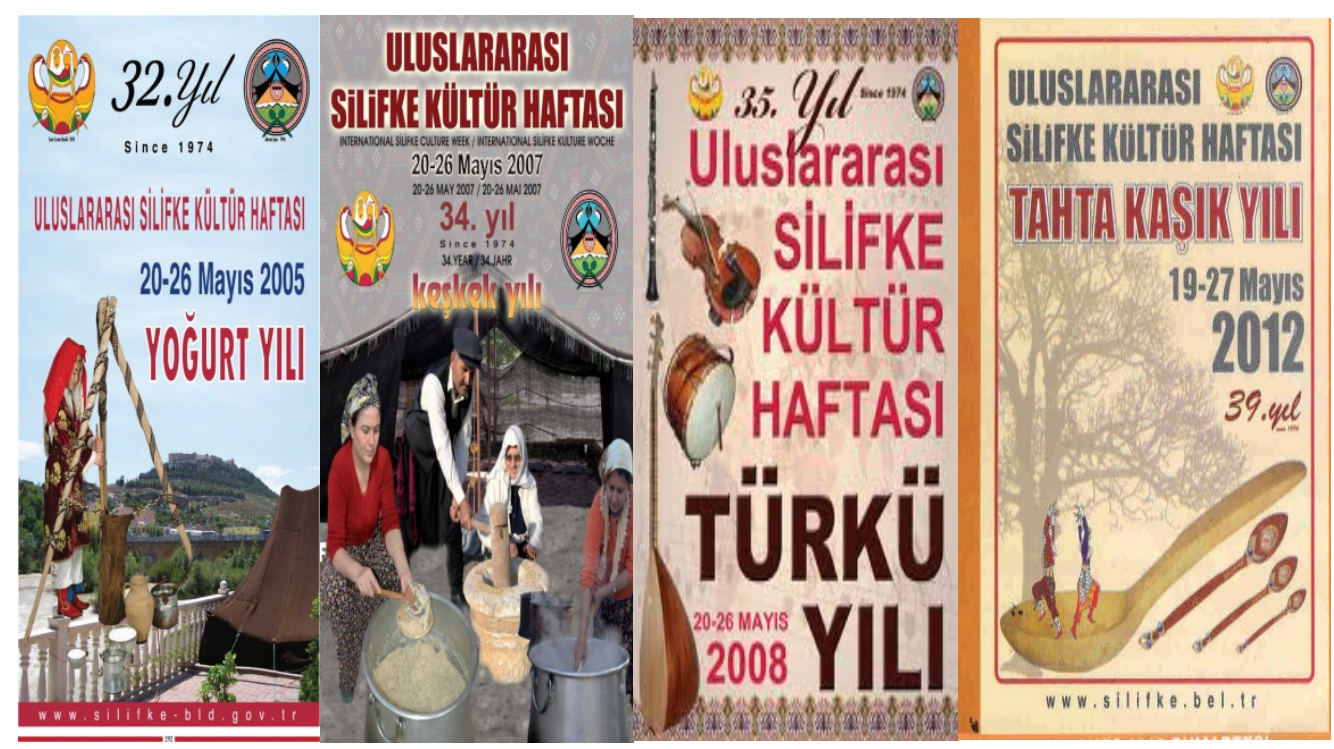

Fotoğraf 12. Festival afişlerinden örnekler

Ayrıca 17 Ocak 2017 yllında imzalanan protokol ile Uluslararası Dünya Folklor Festivalleri Konseyine (CIOFF) üye olunmuştur (URL 1). Birçok ülke festivalini bir çatı altında toplayan bu üyelik ile dünya barışına katkı sağlanmış ve yerelin evrensele taşınmasına bir kapı daha aralanmışırı.

Silifke festivali 1974 yllından beri düzenlenmektedir. Festivaller, topluluk için değerini/anlamını koruduğu ölçüde varlığını sürdürmektedir. Bazı festivaller az çok değişerek günümüze kadar ulaşmış, bazıları zamanla önemini yitirerek terk edilmiş; bazıları gelenekle ilişkilendirilerek yeniden canlandırılırken bazıları da somut anlamda geleneğe ve tarihe yaslanmayan, dolayısıyla baştan yaratılan festival ve kutlamalar olabilmektedir (Yıldırım, 2014, s. 57). Festivalin sürekliliğinde "katılımcılar" ve "düzenleyenler" kuşkusuz ki büyük öneme sahiptir. Bakhtin'in (2005, s. 33-34) ifadeleriyle "Karnaval insanlar tarafindan seyredilen bir gösteri değildir; insanlar onun içinde yaşarlar, herkes ona kattlır, zira karnaval fikrinin kendisi bütün insanları kucaklar. Dünyanın yeniden hayat buluşunun, yenilenişinin, herkesin katıldığ1 özel bir durumudur. İşte karnavalın özü budur; katılımcıların hepsi bu özü canlarıyla kanlarıly hisseder.”. Bu anlamda festivalin sunumunda/içeriğinde yer alan bütün olaylar "katılımcılarla" anlamlıdır. Festivallerin devamlığının sağlanmasında da katılım önemli bir unsurdur. Bu hususta Ali Dalgıç (2018, s. 15) "Festival Ziyaretçilerinin Sadakatlerini Etkileyen Faktörlerin Analizi: Adana Portakal Çiçeği Festivali Örneği” adlı doktora tezinde festival katılımcılarını "sadık" hâle getirmenin, sürecin başarılı bir şekilde gerçekleştirilmesine ve katılımcılara farklı deneyimler sunulmasına bağlı olduğunu; "imaj" ve "deneyim" faktörlerinin bu bağlamda ön plana çıktı̆̆ını ifade eder. "İmaj teorisine göre karar vericiler bir bilgi olarak hafizalarındaki imaja başvururlar. Hafizada yer edinmiş olan imaj ise sonraki davranışları şekillendirme konusunda önemli bir tamamlayıcıdır (Beach ve Mitchell, 1987 akt.: Dalgıç, 2018, s. 12). Bunun yanı sıra bilgi işleme teorisine göre, bireyler öğrendikleri ve sahip oldukları bilgilere (deneyimlere) göre tutum, inanç ve davranışlarını şekillendirmektedir. Yaşanılan olumlu deneyimler sonraki davranışları etkileyeceğinden, etkinlik katılımcılarının olumlu deneyim yaşamaları sadakatlerini güçlendirecektir (Salancik ve Pfeffer, 1978 ak.t: Dalgıç, 2018, s. 52). Dolayısıyla bu süreçte, "festival programı", "festival alanı ve erişebilirlik", "hediyelik eşya ve uygunluk", "güvenlik", "bilgi", ve "yiyecek" gibi unsurlar "sadik" katıllmcilar yaratma konusunda önemlidir (Dalgıç, 2018, s. 169). Silifke festivalinin yolculuğunda kırk altı yıla ulaşttğı düşünülürse bu anlamda başarılı sayılabileceği ortadadır.

\section{Sonuç}

Sonuç olarak, folklorun belirli bir sosyal çevrede, nesilden nesile aktarılanları yaşatma ve aktarma sürecinde işlevini yerine getirebilmesi için; düzenli olarak yerine getirilen ya da getirilme gereksinimi duyulan her tür kültürel uygulamanın, bireyin doğumundan itibaren yakın çevresinden edindiği gözlem ve anlatılarla beslenerek şekillenmesinin önemi bilinen bir gerçekliktir. Festivaller de kültürel belleğe ait unsurların ve değerlerin sürdürülebilirliği için yerel halkın katılımcı süreçlerle bilinçlendirilmesinin ya da gizil bir öğrenme yaratılmasının en etkili ortamlarından birini sunmaktadır. Toplumsal yapının sürekliliğinde ortak belleğe ait ögelerin hatırlanması ve bir disiplin çerçevesinde tekrar1 esastır. Bu süreklilik kültürel belleği oluşturan ögelerin hatırlanmasıyla gerçekleşir. Bu bağlamda her yll ve uzun soluklu olarak 
düzenlenen festivaller toplumsal hafızanın canlı bir biçimde ayakta kalmasına olanak sağlayan etkinliklerden biridir. Bir sonraki nesil için kültürel kimliği yeniden yapılandıracak olan geleneksel bilginin aktarımı için "bir arada olma"yı mümkün kılan kültürel faaliyetler; kültürel hafızanın korunması, geleneğin korunması ve kültürel kodların sürekliliğinin sağlanması anlamlarına gelmektedir.

$\mathrm{Bu}$ çalışma festivallerin kültür aktarımındaki rolü ve önemini belirlemek amacıyla yapılmıştır. Literatürde festivallerin kültür ile ilişkisini çeşitli açılardan inceleyen çalışmalar olmakla birlikte, festivallerin kültür aktarımındaki rolü ve önemini değerlendiren herhangi bir çalışmaya rastlanılmamıştır.

Kültürel mirasın sunumu ve icrasında -korunması bağlamında- ve yerel bilinçlenmenin örneklerinden olan Silifke Belediyesi, uygulamalı halkbilimin amaçladığı teori ve pratiğin birbirini bütünlediği içeriğiyle uygulayarak ve yayarak yaşatmak anlayışının bilinçli ve sistemli örneklerini festival bağlamında ortaya koymuştur. Kültürün aktif bir şekilde işlendiği festival süresince, el sanatları, giyim, yemek gibi yöresel gelenek ve uygulamalar yurt içinden ve yurt dışından gelen katılımcılara tanıtılmaktadır. Dolayısıyla, 46 yıldır devamlı olarak düzenlenen "Uluslararası Silifke Müzik ve Folklor Festivali”nin, yörenin sahip olduğu birikimi (kültürünü ve özelliklerini) yaşatarak gelecek kuşaklara aktarma konusunda başarılı olduğu söylenebilir.

Kamusal eğlence kültürü ve birlikte eğlenme kültürü arac1lı̆ıyla, kentin tarihsel ve kültürel mirasını, yerel kimliğini görünür ve sürdürülebilir kılan; aynı zamanda bireylere kültürel olarak kendilerini gerçekleştirmeleri ve aidiyet duygularını pekiştirmeleri için fırsatlar sunan zengin içerikli festivallerin organizasyonlarında farkındalığı yüksek yerel yönetimlerin önemi yadsınamaz. Bu nedenle ulusal ve kentsel ölçekte kültürel bellekten hareketle özgün ürünler yaratıp tanıtacak ve değerlendirecek olan, ihtiyaç duyulan çok yönlü "kültür profesyonelleri"nden biri, belki de en önemlisi olarak yerel yönetimleri bu grup içerisine dâhil etmek yerinde olacaktır. Nitekim yerel yönetim birimlerinden olan belediyelerle ilgili yasal düzenlemelerde, yerel yönetim birimlerinin kültür sanat hizmetleri de yürütebileceği yer almaktadır. 5393 sayılı Belediye Kanununda Belediyelerin Görev ve Sorumlulukları başlıklı 14. Maddesinde “... kültür ve sanat... hizmetlerini yapar veya yaptırır" ifadeleri ile kanunen yetkilendirildikleri ortaya konulmuştur. Lakin bütçe konusundaki imkân/imkânsılılklar bu hizmetin sunulmasında belirleyici olabileceğinden festivallerin düzenli olarak tertip edilmesinde aksaklıklara ya da içeriğin zenginliğinden feragat edilmesine neden olabilmektedir. Özellikle oldukça düşük bütçeye sahip olan yerel yönetim birimlerinde bu durum daha sık rastlanmaktadır. Bu nedenle bu tür yerel birimler desteklenmeli ki festivaller aracilığyyla yöreye ait kültürün korunması ve aktarımı sağlanabilsin. Bunun için yerel yönetimlere sadece bu amaçla kullanabilecekleri bir kaynak tahsis edilmesi oldukça önemlidir. Maddi imkânların olanaklı olduğu durumlarda ise, bilinçli bir çabayı gerektiren festival organizasyonunda yer alan komitenin de bu anlamda farkındalığ1 yüksek üyelerden oluşması ayr1 bir zorunluluktur. Bu anlamda yerel yönetimlerde kültür birimlerinde görevli yönetici ve personellerin yetkin kişilerden oluşturulması önemlidir. Bu konuda üniversitelerin Türk Halk Bilimi, Kültürel Miras ve Kültür Yönetimi, Kültürel Miras ve Turizm alanlarından mezun kişiler istihdam edilebilir.

Bu tür organizasyonların sürdürülebilirliği, yerel halkın desteği ve katıllımı ile mümkündür. Katılım ve sürekliliğin sağlanması hususunda ise festival organizasyonunu çekici hâle getirmek önemlidir. Bu sayede festival katılımcıları "sadık" hâle gelecektir. Bu da festivallerin kültür aktarımındaki rolünü daha işlevsel kılacaktır. Ayrıca festivalin, planlamadan uygulamaya tüm sürecinde kültürel konularda faaliyet gösteren sivil toplum kuruluşları ve kurumlar ile işbirliği içinde olunması bir diğer husustur. Bu sayede yerel kültürle olan bağ kopmadan, festival geleneğinin devamlllı̆̆1 sağlanmış ve yerel halkın kendi kültürüne yabancılaşmasının önüne geçilmiş olacaktır.

Bu çalışmanın yerel yönetimlere ve uygulayıcılara sunacağı bir diğer öneri ise, Silifke Belediyesi ve festivalin mimarları olan düzenleme komiteleriyle etkileşimde bulanarak, Silifke Belediyesi'nin 46 y1llk festival düzenleme belleğini ve tecrübelerini öğrenmeleridir.

Ayrıca bu çalışmada -1974 yılından bu yana düzenlenen Uluslararası Silifke Müzik ve Folklor Festivali özelinde- kültürün aktarımında ve korunmasında festivallerin işlevi ve önemi değerlendirilmiş; bu sürecin aktörleri olan topluluk, grup ve bireylerin aktif katılımı ile yerel yönetimlerin farkındalığının öneminin ortaya konulması, festival alanında çalışan uzmanlara/araştırmacılara/düzenleyicilere yeni bakış açıları kazandırarak uygulamalara katkı sunması beklenmektedir. 


\section{Etik Beyan}

"Gelenekten Geleceğe Yöresel Kültürün Tasıınmasında Festivallerin Rolü" başlıklı çalışmanın yazım sürecinde bilimsel kurallara, etik ve alıntı kurallarına uyulmuş; toplanan veriler üzerinde herhangi bir tahrifat yapılmamış ve bu çalışma herhangi başka bir akademik yayın ortamına değerlendirme için gönderilmemiştir. $\mathrm{Bu}$ araştırmada doküman incelemesi yapıldığından etik kurul kararı zorunluluğu bulunmamaktadir.

\section{Kaynakça}

Ada, S. (2011). İstanbul'un festivalleri. İstanbul: Bilgi Üniversitesi Yayınları.

Akarpınar, R. B. (2004). Tarım toplumundan sanayi toplumuna geçişte panayır-sergi-fuar-festivalin durumu ve Türkiye örneği. Millî Folklor. 64, 25-36.

Assmann, J. (2015). Kültürel bellek eski yü̈sek kültürlerde yą̌, hatırlama ve politik kimlik (Çev: Ayşe Tekin). İstanbul: Ayrintı Yayınları.

Atak, O., Tatar, S. ve Tunaseli, A. (2017). Kültürel miras oluşumunda festivallerin yeri ve önemi: Fethiye Müzik Köyü üzerine bir değerlendirme. Uluslararası Sosyal Araștırmalar Dergisi, 10(52), 1396-1409.

Bakhtin, M. (2005). Rabelais ve dünyası. (Çev.: Çiçek Öztek). İstanbul: Ayrıntı Yayınları.

Balkaya, A. (2013). Sarıkamış'ta bilinmeyen yüzyıllık sosyal olumlama argümanı: karaurgan karakucak güreşleri. $<$ https://docplayer.biz.tr/21620841-Sarikamis-ta-bilinmeyen-yuzyillik-sosyal-olummlama-argumani-karaurgankarakucak-guresleri.html> [Erişim Tarihi: 26.03.2019]

Bayrakc1, E. (2019). Yerel yönetimler. Konya: Dizgi Ofset.

Buzcu, Z. ve Oğuz, S. (2019). Festival ziyaretçilerinin algıladıkları değer, memnuniyet ve sadakatin festival kalitesi ile olan ilişkisi: Adana kebap-şalgam festivali örneği. Journal of Tourism and Gastronomy Studies, 7(4), 3140-3155.

Çıblak Coşkun, N. (2018). Mersin ili koy seyirlik oyunlarından deve bollatması ve aşuk maşuk oyunu. Karadeniæ. 39(39), 128-140.

Dalgıç, A. (2018). Festival ziyaretçilerinin sadakatlerini etkileyen faktörlerin analiæi: Adana portakal çiģeği festivali örneği (Doktora Tezi). Mersin Üniversitesi, Sosyal Bilimler Enstitüsü, Mersin.

Halbwachs, M. (2017). Kolektif hafıza (Çev: B. Barıș). Ankara: Heretik Basın Yayın.

İlban, M. O. ve Kömür, T. (2019). destinasyon markalaşmasında festival turizminin rolü: Ayvalık uluslararası zeytin hasat günleri örneği. Seyahat ve Otel İsletmecilĭgi Dergisi, 16(2), 274-295.

İmirgi, A. (2005). Festival kavramı üzerine düşünceler. Milli Folklor, 65, 29- 36.

Karaca, O.B., Yıldırım, O. ve Çakııı, C. (2017). Adana Uluslararası Portakal Çiçeği Karnavalına katılan ziyaretçilerin alg1 ve memnuniyetleri. Mustafa Kemal Üniversitesi Sosyal Bilimler Enstitüsü Dergisi, 14(37), 222-239.

Kaya Erdoğan, E. (2011). Hizmet, girişim, kültür ekseninde İstanbul'da ilçe festivalleri. Istanbul'un festivalleri. (Derleyen: Serhan Ada). İstanbul: Bilgi Üniversitesi Yayınları.

Keleş, R. (2000). Yerinden yönetim ve siyaset. İstanbul: Cem Yayınevi.

Kladou, S. (2011). Kültür festivalleri. Istanbul'un festivalleri (Derleyen: Serhan Ada). İstanbul: Bilgi Üniversitesi Yayınları.

Nadaroğlu, H. (2011). Mahalli idareler teorisi, ekonomisi, uygulaması (7. Baskı). İstanbul: Beta Basım Yayım Dağıtım.

Oğuz, M. Ö (2013). Küreselleşme ve uygulamal halkebilimi. Ankara: Akçă̆ Yayınları.

Özdemir, N. (2008). Kültürel Ekonomik İmge Olarak Nasreddin Hoca. Millî Folklor, 77, 11- 20.

Özdemir, N. (2012). Kent kültürü, yerel medya ve kültür ekonomisi. Kültür ekonomisi ve yönetimi (Seçki). Ankara: Hacattepe Yayıncliık \& Kitapçılık Ltd. Şti.

Prentice, R. ve Andersen, V. (2003). Festival as creative destination. Annals of Tourism Research, 30(1), 7-30.

Saçlı, Ç. (2020). Festival memnuniyeti ile kültürel etkileşim arasındaki ilişki üzerine bir araştırma: Silifke Uluslararası Müzik ve Folklor Festivali örneği. Türk Turizm Araștırmalar Dergisi, 4(1), 505-521.

Silifke Belediye Başkanlığ1 (2013). 40. Yılında Silifke Festivali Taribi 1974-2012 (Yay. Haz: L. Uğur). Ankara: Gökçe Ofset Matbaacilik.

Smith, R. J. (2009). "Festival ve kutlamalar" (Çev.: Sibel Keskin). Halkbiliminde kuramlar ve yaklaşımlar 3. (Yay. Haz. M. Öcal Oğuz, Selcan Gürçayır, Sunay Çalış). Ankara: Geleneksel Yayınları, 341-350.

Stoeltje, B. J. (2009). Festival (Çev. Petek Ersoy). Halkbiliminde kuramlar ve yaklaşımlar 3. (Yay. Haz. M. Ö. Oğuz, S. Gürçayır, S. Çalış). Ankara: Geleneksel Yayınları.

Süslü, C., Eryılmaz, G., ve Demir, E. (2019). Festival turizminin ekonomik kalkınmaya etkisi: Silifke Uluslararası Müzik ve Folklor Festivali. Türk Turiẓm Araștırmalar Dergisi, 3(4), 1047-1090.

Şeyben, B. Y. (2011). Açıkhava etkinlikler: fetih şenlikleri, cumhuriyet kutlamaları ve hıdırellez. İstanbul'un festivalleri. (Derleyen: Serhan Ada). İstanbul: Bilgi Üniversitesi Yayınları, 53-78.

Tayfun, A. ve Arslan, E. (2013). Festival turizmi kapsamında yerli turistlerin Ankara Alışveriş Festivali’nden memnuniyetleri üzerine bir araştırma. İsletme Araştırmalan Dergisi, 5(2), 191-206.

Turner, V. (2018). Ritüeller yapr ve anti-yapı (Çev.: Nur Küçük). İstanbul: İthaki Yayınları.

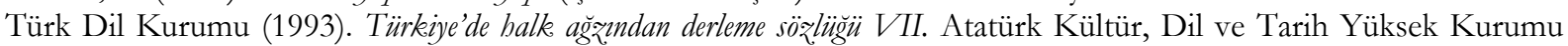
Türk Dil Kurumu Yayınları, Say1 211/7. Ankara: Ankara Üniversitesi Basımevi. 
URL 1: https://www.milliyet.com.tr/yerel-haberler/mersin/silifke-muzik-ve-folklor-festivali-cioffa-uye-oldu11787199 [Erişim Tarihi: 17.10.2020]

Yeşilyurt, N. (2018). Etnospor Kültür Festivali'nin sosyolojik ve kültürel açıdan değerlendirilmesi ve medyanın önemi. Uluslararası Din ve Medya Sempozyumu, Balıkesir.

Yıldırım, A. ve Şimşek, H. (2016). Sosyal bilimlerde nitel araştırma yöntemleri. Ankara: Seçkin.

Yıldırım, İ. (2014). Yöresel festival üzerine görsel etnografik bir inceleme: Ankara "Beypazar Festivali” örneği (Doktora Tezi). Ankara Üniversitesi, Sosyal Bilimler Enstitüsü, Ankara.

\section{EXTENDED ABSTRACT}

Festivals are considered as meetings, celebrations where people can have fun together at national or local level. Festivals have important functions in terms of social cohesion, providing individual happiness and sustaining/transferring culture. Festival communication actively connects the participants, for this reason, social practices strengthen the bonds that connect the individual to the social group, as well as contribute to the socialization process as it is realized within the community. They are organizations in which the elements belong to cultural memory shared by the members of society in its content are presented within a certain time and place with the mission of bringing community together. Socialization, sense of belonging and the function of group awareness. Festivals are events where the culture transfer is vividly provided, evaluating past in terms of nourishing now and future and are one of the most effective environments for the sustainability of cultural heritage by raising the awareness of the local community through participatory processes or creating secret learning. In the organization of these organizations, where the cultural transmission is carried out intensively, the municipalities, which are the local government units, are actively involved and have been authorized by law to provide such cultural and artistic services. By the way of "public entertainment culture" and collective culture of entertainment that makes the city's historical, cultural heritage and local identity visible and sustainable; at the same time, the role of high-level local governments in the organization of rich content festivals that offer opportunities for individuals to realize themselves both culturally and to reinforce their sense of belonging, cannot be denied. For this importance, from cultural memory perspective, organizing cultural and original festivals in local, national and international scale, local governments, which will enable the transfer of culture and enable people to have a homogeneous enjoyment and coexistence, appear as one of the most needed and multi-faceted "cultural professionals" and perhaps the most important. In the legal regulations regarding municipalities, which are among the local government units, it is stated that local government units can also provide culture and arts services. It is stated in the Municipality Law No. 5393, Article 14 titled Duties and Responsibilities of Municipalities, that they are authorized by law with the statement “... it performs culture and arts services or have them performed". However, as the possibilities / impossibilities regarding the budget can be decisive in the provision of this service, they may cause problems in the regular organization of the festivals or the richness of the content. In cases where financial means are possible, it is a separate obligation that the committee, which takes part in the festival organization, which requires a conscious effort, consists of highly aware members in this sense. In different provinces and districts in Turkey; although their names, cultural and artistic aspects, or even their content are different from each other, many festivals are organized. International Silifke Music and Folklore Festival, which serves many purposes, is one of them.

In this study it is aimed to evaluate the International Silifke Culture Week activities organized every year in Silifke since 1974 and the function and importance these activities within the scope of cultural conservation as the finest samples of local awareness and in the context of the applications made for the purpose of applying and spreading as to protect and transfer to future generations according to the provisions of "Intangible Cultural Convention on Protection of Heritage" which was adopted in 17th October 2003 by UNESCO, United Nations Educational, Scientific and Cultural Organization, and participated by Turkey in 2006 .

In the selection of the "International Silifke Culture Week" as a sample, it is decisive that it has been periodically organized for forty five years since 1974. The data of this study, in which the document review is used as one of the qualitative research methods, has been obtained from the documents on the "International Silifke Culture Week" published between 1974-2018 in the archive of the Municipality of Silifke. In the continuity of the festival, "participants" and "organizers" have undoubtedly great importance, and festivals continue to exist as long as they maintain their value / meaning for the community. It is an event that "International Silifke Culture Week", which is a forty-six-year journey, is an activity not as a spectacle watched by human beings but with its content that is tied to tradition and with 
historical content; and in the context of the, performance, presentation and conservation of cultural memory, provides the conscious and systematic examples of an understanding of "applying" and "spreading" the theory and practice aimed by the applied folkloristic with the content integrated with each other in the context of the festival.

In this context, annual and long-term festivals are one of the events that enable the social memory to survive vividly. Cultural activities that enable "unity" for the transmission of traditional knowledge that will reconstruct cultural identity for the next generation; it means preserving cultural memory, preserving tradition and ensuring the continuity of cultural codes. In this context, it is stated that festivals can be used / used as a means of transmission in the cultural preservation process; it has been found that it includes more than a "touristic" and "commercial" activity. 